\title{
Manajemen Panen Kelapa Sawit (Elaeis Guineensis Jacq.) Di Gunung Sari Estate, Kalimantan Selatan
}

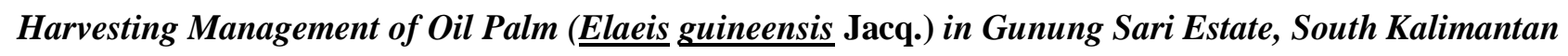

\author{
Midian Romeo Siregar dan Ade Wachjar*
}

Departemen Agronomi dan Hortikultura, Fakultas Pertanian, Institut Pertanian Bogor

(Bogor Agricultural University), Jl. Meranti, Kampus IPB Darmaga, Bogor 16680, Indonesia

Telp.\&Faks.62-251-8629353 e-mail agronipb@indo.net.id

*Penulis untuk korespondensi: wachjarade@yahoo.co.id

Disetujui 6 November 2017/Published online 14 November 2017

\begin{abstract}
The research was conducted in Gunung Sari Estate, South Kalimantan from February until June 2011. Activities performedduring the internshipis a field worker for one month, as assistant foreman for one month, as assistant chief of the garden for two months. The purpose of the internship is improve knowledge, gain work experience and studying the management aspects of harvesting oil palm, both technical and managerial aspects. The primary data were obtained directly from the field by doing discussions or interviews with the foreman and assistant division as well as through direct observation in the field. The secondary data were obtained from the company data or company records. Based om observation during research can be conclude that the main issues in harvesting was late harvest interval, this was due to defiency harvest labour, harvest basis was not reached and harvest labout absenteeism was high. Source of losses in Gunung Sari Estate was unharvested bunches, unripe bunches, empty fruit bunch and uncollected lossfruit. In general harvesting management in Gunung Sari Estate have to improved to minimaze losses.
\end{abstract}

Keyword : harvesting management, oil palm, source of losses

\begin{abstract}
ABSTRAK
Penelitian ini dilakukan di Gunung Sari Estate, agang ini dilakukan di Gunung Sari Estate, Kalimantan Selatan, dari Februari sampai Juni 2011. Kegiatan yang dilakukan selama penelitian sebagai seorang pekerja lapangan selama satu bulan, sebagai asisten mandor selama satu bulan, sebagai asisten kepala kebun selama dua bulan. Tujuan dari penelitian adalah meningkatkan pengetahuan, mendapatkan pengalaman kerja dan mempelajari aspek pengelolaan kelapa sawit panen, aspek teknis dan manajerial. Data primer diperoleh langsung dari lapangan dengan melakukan diskusi atau wawancara dengan mandor dan asisten divisi serta melalui pengamatan langsung di lapangan. Data sekunder diperoleh dari perusahaan data atau catatan perusahaan. Berdasarkan pengamatan selama penelitian dapat disimpulkan bahwa masalah utama dalam panen terlambat Interval panen, hal ini disebabkan kekurangan tenaga kerja panen, dasar tidak Mencapai panen, dan absensi tenaga kerja panen tinggi. Sumber kerugian di Gunung Sari Estate adalah Tandan dipanen, Tandan mentah, tandan kosong dan kehilangan buah yang belum dikumpulkan. Pada panen umum dalam manajemen Gunung Sari Estate telah ditingkatkan untuk meminimalkan kerugian.
\end{abstract}

Kata kunci : kelapa sawit, manajemen pemanenan, sumber kehilangan 


\section{PENDAHULUAN}

Kelapa sawit merupakan salah satu komoditas perkebunan andalan di Indonesia saat ini. Menurut Pardamean (2008) komoditas kelapa sawit cocok dikembangkan, baik berbentuk pola usaha perkebunan besar maupun skala kecil untuk petani pekebun. Pertumbuhan kelapa sawit lebih tahan menghadapi berbagai kendala dan masalah dibandingkan tanaman lain. Mangoensoekarjo dan Semangun (2005) menyatakan bahwa komoditas kelapa sawit memiliki peluang bisnis yang besar dan dapat menciptakan lapangan kerja yang mengarah kepada kesejahteraan masyarakat dan sebagai sumber devisa negara.

Kelapa sawit merupakan sumber minyak nabati yang penting. Kelapa sawit dapat diolah menjadi minyak sawit yang dikenal sebagai Crude Palm Oil (CPO) dan Palm Kernel Oil (PKO). Crude Palm Oil (CPO) dan Palm Kernel Oil (PKO) dapat diolah menjadi bermacammacam produk lanjutan dengan bermacammacam kegunaan seperti minyak goreng, mentega, sabun, kosmetika, dan obat. Selain itu, minyak kelapa sawit dapat menjadi substitusi bahan bakar minyak yang saat ini sebagian besar dipenuhi dari minyak bumi (Setyamidjaja, 2006).

Pemanenan merupakan hal yang sangat penting dalam kegiatan produksi tanaman kelapa sawit. Pelaksanaan pemanenan kelapa sawit berpengaruh langsung terhadap kualitas minyak yang dihasilkan. Kualitas minyak yang dihasilkan bergantung pada kriteria panen buah yang layak dipanen. Menurut Pahan (2008) pelaksanaan akan berjalan normal bila dikelola dengan baik. Oleh karena itu, kegiatan pemanenan kelapa sawit sawit harus dilakukan sebaik-baiknya agar diperoleh target produksi dengan kualitas yang memenuhi permintaan pasar.

Keberhasilan panen dan produksi sangat bergantung pada bahan tanam yang digunakan untuk panen, kelancaran transportasi serta faktor pendukung lainnya seperti organisasi panen yang baik, keadaan areal dan insentif yang disediakan (Lubis, 2008). Pelaksanaan pemanenan kelapa sawit yang tepat meliputi penentuan kriteria panen, penyebaran dan rotasi panen, penyediaan tenaga kerja yang terampil, teknis panen, pengumpulan hasil dan pengawasan serta pengangkutan panen. Penelitian ini bertujuan mempelajari dan menganalisis permasalahan dalam pengelolaan pemanenan agar dapat memberikan masukan yang efektif dan efisien dalam kegiatan pemanenan.

\section{BAHAN DAN METODE}

Penelitian dilaksanakan di Gunung Sari Estate, Kalimantan mulai bulan Februari 2011 sampai Juni 2011. Penelitian dilakukan meliputi kegiatan teknis dan kegiatan manajerial yang disesuaikan dengan jadwal perkebunan. Kegiatan penelitian yaitu pemeliharaan dan pemanenan. Kegiatan pemeliharaan meliputi pengendalian gulma secara manual dan kimia, pemupukan organik dan anorganik, penanaman benefical plant dan rawat jalan. Kegiatan pemanenan meliputi perencanaan pemanenan hingga pengangkutan TBS ke pabrik.

Pengumpulan data meliputi pengambilan primer dan sekunder. Data primer merupakan informasi yang diperoleh secara langsung melalui pengamatan yang dilakukan serta diskusi langsung KHL, mandor dan asisten kebun. Data primer yang diperoleh yaitu kriteria matang panen (kualitas potong buah), perhitungan angka kerapatan panen dan taksasi produksi, dan losses akibat pelaksanaan panen. Kriteria matang panen dilakukan dengan mengamati mutu buah sesuai kriteria matang panen yang diterapkan di Divisi 2. Pengamatan dilakukan di masing-masing kemandoran dengan mengambil 15 TPH sampel perkemandoran. Perhitungan angka kerapatan panen (AKP) dan taksasi produksi dilakukan dengan mengambil pokok sampel sebanyak $10 \%$ dari total populasi dalam satu blok yang diambil secara acak. Tandan buah segar tidak terpanen dan kualitas kutip brondolan dilakukan dengan mengamati kualitas kerja pemanenan (cutter) dan pembrondol (picker). Losses brondolan akibat pemotongan gagang panjang dilakukan dengan menghitung jumlah brondolan yang terikut dalam potongan gagang panjang oleh pemanenan.

Data sekunder diperoleh dari laporan manajemen (bulanan, semesteran, tahunan) dan studi pustaka. Data sekunder yang diperoleh yaitu data elevasi, curah hujan, data produksi dan historis produksi. Data yang diperoleh kemudian dianalisis dengan metode deskriptif kualitatif.

\section{HASIL DAN PEMBAHASAN}

\section{Kondisi umum}

Gunung Sari Estate (GSE) terletak di Desa Bayansari, Kecamatan Angsana, Kabupaten Tanah bumbu, Provinsi Kalimantan Selatan dengan jarak $\pm 200 \mathrm{~km}$ dari Banjarmasin dengan ketinggian $\pm 15 \mathrm{~m}$ diatas permukaan laut (dpl). Rata-rata curah hujan tahunan GSE dalam kurun waktu sembilan tahun terakhir (2002-2010) adalah 2528 mm dengan jumlah hari hujan rata-rata 159 
hari. Curah hujan tertinggi terjadi pada bulan Juni (rata-rata $346 \mathrm{~mm}$ ), sedangkan curah hujan terendah terjadi pada bulan September (rata-rata $110 \mathrm{~mm}$ ). Rata-rata jumlah bulan basah (BB) dan bulan kering (BK) berturut-turut yaitu 8.66 dan 2.22 bulan. Menurut kelas iklim SchmidthFerguson, keadaan iklim di GSE termasuk dalam tipe iklim B, yaitu daerah basah dengan vegetasi hutan hujan tropika. Berdasarkan hasil analisis tanah yang dilakukan oleh Minamas Research Centre (MRC) pada tahun 2006, jenis tanah di GSE tergolong ke dalam ordo oxisol dengan seri tanah MM-18 Petroferric Hapludox dan MM-19 Plinthic Hapludox.

Tanaman kelapa sawit yang diusahakan adalah Tenera yang merupakan hasil persilangan antara Dura dan Psifera. Bibit yang digunakan berasal dari Pusat Penelitian Kelapa Sawit (PPKS) dan PT Socfindo. Tanaman kelapa sawit ditanam dengan jarak tanam 9,2 m x 9,2 m x 9,2 $m$ dengan pola tanam berbentuk segitiga sama sisi dengan standar populasi 136 pokok/ha. Produktivitas kelapa sawit di Kebun Gunung Sari dari tahun 2005 - 2010 yaitu 22.77, 20.68, 20.54, 16.99, dan 23.22 ton TBS/ha/tahun.

\section{Penetapan target}

Tanaman kelapa sawit siap dipanen ketika berumur 30 bulan. Apabila memasuki tahap menghasilkan, tanaman akan terus berproduksi hingga umur 25 tahun. Pada periode menghasilkan, perlu dilakukan perencanaan panen yang rutin agar produksi yang dihasilkan sesuai dengan potensi produksi tanaman. Perencanaan panen dilakukan setiap tahun, semester, dan harian. Dasar perencanaan panen adalah potensi produksi. Penentuan target tahunan mengacu pada standar produksi yang berdasarkan pada umur tanaman dan kelas lahan. Data produksi selama beberapa tahun terakhir juga dijadikan dasar bagi penentuan target selama setahun. Target satu tahun didistribusikan pada bulan JanuariDesember dan dikelompokkan antara semester 1 dan semester 2.

Target semester disusun setiap enam bulan. Untuk menetapkan target per semester dilakukan sensus buah dan bunga. Produksi tandan buah segar (TBS) ditentukan oleh jumlah bunga yang kemudian berkembang menjadi buah. Proses perkembangan dari bunga menjadi buah membutuhkan waktu sekitar 5-6 bulan. Dengan menghitung jumlah TBS dapat diketahui produksi untuk enam bulan ke depan. Pengamatan dilakukan dengan mengambil $10-15 \%$ pokok sampel dari jumlah pokok produktif berdasarkan tahun tanam masing-masing divisi. Pengamatan dilakukan dua kali dalam setahun yaitu pada bulan Desember dan Juni.

Tabel 1. Target dan realisasi produksi yang dapat dicapai Divisi 2 pada bulan Januari-Mei 2011

\begin{tabular}{lccccc}
\hline \multirow{2}{*}{ Produksi } & \multicolumn{3}{c}{ Produksi TBS } & Realisasi terhadap & $\begin{array}{c}\text { Realisasi terhadap target } \\
\text { potensi (\%) }\end{array}$ \\
\cline { 2 - 4 } & Potensi (kg) & Target $(\mathrm{kg})$ & $\begin{array}{c}\text { Realisasi } \\
(\mathrm{kg})\end{array}$ & 103.59 & 90.32 \\
Januari & 1632150 & 1871910 & 1690672 & & 95.65 \\
Februari & 1530140 & 1476060 & 1411920 & 92.27 & 143.12 \\
Maret & 1632150 & 1480510 & 2118900 & 129.82 & 135.53 \\
April & 2040180 & 1633860 & 2214410 & 108.54 & 125.26 \\
Mei & 2142190 & 1869610 & 2341900 & 109.32 & \\
\hline
\end{tabular}

Sumber : kantor Divisi 2 GSE (2011)

Berdasarkan pada tabel 1 terlihat bahwa Divisi 2 rata - rata mampu mencapai potensi produksi kecuali pada bulan Februari, yang hanya mencapai $92,27 \%$ dari potensi produksi yaitu $1411920 \mathrm{~kg}$. Tidak tercapainya potensi produksi diakibatkan oleh seringnya pemanen tidak dapat menyelesaikan hancaknya atau tidak mencapai basis pada hari panen. Disamping itu jumlah hari kerja (HK) pada bulan Februari cukup rendah dibanding bulan lain yaitu 1429 HK dengan jumlah HK siap borongnya 1010 kg/HK. Tidak tercapainya potensi produksi pada bulan Februari juga dapat diakibatkan oleh rendahnya persentase kematangan buah. Rendahnya persentase kematangan buah diakibatkan oleh rendahnya curah hujan pada bulan Februari, yaitu $53 \mathrm{~mm}$ dengan jumlah hari hujan 13 hari. Untuk lebih jelasnya dapat dilihat pada Tabel 2.

Tidak selesainya hancak pada hari panen menyebabkan pusingan menjadi tinggi. Pusingan panen pada bulan Februari belum mencapai standar yakni pusingan 6/7 atau minimal 4 kali dipanen pada satu bulan. Pusingan panen pada Bulan Februari termasuk tinggi yaitu 2.64. Kurangnya tenaga panen mengakibatkan tidak optimalnya penggalian potensi produksi. Pada bulan Februari jumlah tenaga pemanen yang tercatat di divisi 2 adalah 39 orang sementara standar jumlah pemanen di Divisi 2 adalah 44 orang, sehingga masih kekurangan 5 orang tenaga pemanen. Dengan menambah tenaga pemanen diharapkan mampu meningkatkan efisiensi untuk 
mencapai potensi produksi yang telah ditetapkan. Menurut Lubis (2008) keberhasilan dalam pencapaian produksi sangat dipengaruhi oleh bahan tanam yang digunakan, tenaga panen dengan kapasitas kerjanya, kelancaran transportasi serta faktor pendukung lainnya yakni keadaan areal dan organisasi yang efektif.

Tabel 2. Jumlah hari kerja (HK), jumlah pemanen, pusingan dan curah hujan di Divisi 2 pada bylan JanuariMei 2011

\begin{tabular}{lcrrrrrrr}
\hline \multicolumn{1}{c}{ Bulan } & Luas (ha) & HK kerja & $\begin{array}{c}\text { HK siap } \\
\text { borong }\end{array}$ & $\begin{array}{c}\text { Output } \\
\text { (kg/HK) }\end{array}$ & $\begin{array}{c}\text { Jumlah } \\
\text { pemanen }\end{array}$ & Pusingan & $\begin{array}{c}\text { Jumlah } \\
\text { hari hujan }\end{array}$ & $\begin{array}{c}\text { Curah } \\
\text { hujan } \\
\text { (mm) }\end{array}$ \\
\hline Januari & 990 & 1596 & 1277 & 1059 & 38 & 3.17 & 18 & 203 \\
Februari & 990 & 1429 & 1010 & 988 & 39 & 2.64 & 13 & 53 \\
Maret & 990 & 1774 & 1422 & 1234 & 40 & 3.03 & 20 & 221 \\
April & 990 & 1746 & 1488 & 1268 & 40 & 3.1 & 16 & 238 \\
Mei & 990 & 1837 & 1386 & 1275 & 41 & 3.89 & 15 & 165 \\
\hline
\end{tabular}

Sumber : Kantor besar GSE (2011)

Angka kerapatan panen (AKP) dan taksasi produksi

Pengamatan terhadap angka kerapatan panen dilakukan setiap hari untuk dapat mentaksasi produksi besok hari. Pada saat melaksanakan penelitian, penulis melakukan taksasi buah bersama mandor panen. Angka Kerapatan Panen dihitung dengan menggunakan pohon sampel. Pohon sampel diambil sebanyak $10 \%$ dari total populasi pada satu blok. Pengambilan pokok sampel ditentukan dengan memilih jalur secara acak pada blok sampel. Angka Kerapatan Panen dapat dihitung dengan rumus :

$$
A K P=\frac{\text { jumlah buah merah }}{\text { pokok sampel }} \times 100 \%
$$

Angka Kerapatan Panen digunakan untuk menghitung taksasi produksi. Taksasi produksi adalah kegiatan untuk memperkirakan produksi TBS kebun yang akan dihasilkan pada periode pemanenan tersebut yang dapat digunakan untuk memperkirakan produksi, jumlah tenaga kerja panen dan alat pengangkutan yang dibutuhkan untuk mengangkut TBS. Taksasi produksi dilakukan di Blok F27 adalah 25.5 ton, dengan contoh perhitungan :

$$
\begin{array}{ll}
\text { Pokok sampel } & : 400 \text { pokok } \\
\text { Jumlah buah merah } & : 131 \text { tandan }
\end{array}
$$

Tabel 3. Standar kematangan (Ripeness standard) buah

$$
\text { BJR : } 20.49 \mathrm{~kg}
$$

Total pokok produktif : 3806 pokok

$$
\begin{aligned}
\text { AKP } & =\frac{\text { jumlah buah merah }}{\text { pokok sampel }} \times 100 \% \\
& =\frac{131}{400} \times 100 \% \\
& =32.75 \% \approx 33 \%
\end{aligned}
$$

Perkiraan produksi $=\mathrm{AKP} \times \mathrm{BJR} \times$ Total pokok produktif

$$
\begin{aligned}
& =0.33 \times 20.49 \times 3806 \\
& =25540 \mathrm{~kg}(25.5 \text { ton })
\end{aligned}
$$

Menurut perhitungan sensus harian di atas, persentase kerapatan panen adalah 33\%. Berdasarkan angka kerapatan tersebut, maka diperkirakan produksi yang keluar dari Blok F27 adalah 25.5 ton. Jumlah truk yang dibutuhkan juka kemampuan rata-rata angkut buah 8 ton TBS per tripnya adalah 3 truk (3 trip).

\section{Kriteria matang panen}

Penentuan kriteria matang panen sangat penting dilakukan agar pemanen memotong tandan buah yang tepat. Secara teori, tandan buah yang ideal untuk dipanen adalah saat kandungan minyak maksimal dalam daging buah dan kandungan asam lemak bebas yang serendah mungkin.

\begin{tabular}{llc}
\hline Jenis Buah & Kriteria & Batas Toleran \\
\hline Unripe (Mentah) & $0-4$ brondolan lepas/ janjang & $0 \%$ \\
Under Ripe (Kurang Matang) & $5-9$ brondolan lepas/ jangjang & $<5 \%$ \\
Ripe (Matang) & $\geq 10$ brondolan lepas/ janjang & $>95 \%$ \\
Empty Bunch(Janjang Kosong) & $>95 \%$ brondolan lepas/ jangjang & $0 \%$ \\
Longstalk (Gagang panjang) & panjang gagang $>5 \mathrm{~cm}$ & $0 \%$ \\
Old Bunch (Buah Restan) & Lebih dari 48 jam & $0 \%$ \\
\hline
\end{tabular}

Sumber : manual referensi agronomi minamas plantation Indonesia (2008) 
Kriteria matang panen di Divisi 2 mengikuti Minimum Ripeness Standard (MRS) atau kriteria matang panen berdasarkan atas jumlah brondolan yang lepas secara alami dari tandan buah yang matang yaitu sekurangkurangnya terdapat lima brondolan per janjang di piringan sebelum panen. Kriteria matang panen yang berlaku di Divisi 2 dapat dilihat pada Tabel 3. Tujuan penerapan kriteria matang buah adalah agar diperoleh tandan buah segar (TBS) yang layak olah dengan kandungan ALB serendah mungkin. Kandungan asam lemak bebas (ALB) buah juga dipengaruhi oleh kualitas buah saat dipanen. Oleh karena itu terdapat kriteria matang panen yang dibedakan menjadi beberapa fraksi. Pada setiap tingkatan fraksi kematangan buah memiliki rendemen minyak dan kandungan ALB yang berbeda, seperti yang disajikan pada Tabel 4 .

Tabel 4. Hasil pengamatan kualitas potong buah di Divisi 2 GSE

\begin{tabular}{ccc}
\hline Fraksi Buah & Rendemen Minyak & Kadar Asam Lemak Bebas \\
\hline 0 & 16 & 1.6 \\
1 & 21.4 & 1.7 \\
2 & 22.1 & 1.8 \\
3 & 22.2 & 2.1 \\
4 & 22.2 & 2.6 \\
5 & 21.9 & 3.8 \\
\hline
\end{tabular}

Sumber : Lubis (2008)

Tabel 4, panen pada fraksi 0 akan merugikan karena rendemen minyaknya masih rendah, sedangkan pada fraksi 4 dan 5 juga merugikan karena memiliki kadar ALB yang tinggi. Dari hasil pengamatan kualitas potong buah di Divisi 2 (Tabel 5), total buah mentah yang dipanen adalah $0.7 \%$, buah under ripe 2.33 $\%$, buah ripe $88.11 \%$, dan buah empty bunch 8.9 $\%$. Pemanenan buah unripe merupakan salah satu sumber losses. Persentase pemanenan buah unripe di atas standar, hal ini terjadi karena sebagian pemanen kurang memahami instruksi mandor mengenai buah yang boleh dipanen dan terkadang untuk memenuhi basis, pemanen memanen buah unripe. Oleh karena itu, perlu diberikan peraturan yang jelas bagi pemanen supaya tidak terjadi pemanenan buah mentah yang merugikan perusahaan.

Kualitas TBS hasil panen yang baik yaitu pada fraksi 2 dan 3 (buah ripe). Persentase buah ripe masih di bawah standar yaitu 88.11, sementara persentase empty bunch tinggi yaitu 8.90. Tingginya persentase empty bunch yang dipanen menunjukkan bahwa pusingan panen yang dilakukan tinggi. Tingginya pusingan panen disebabkan oleh banyaknya tenaga pemanen yang tidak masuk kerja, banyaknya libur, atau karena cuaca yang buruk. Pemanenan buah empty bunch akan merugikan perusahaan berdasarkan kandungan minyak serta kandungan ALBnya.

Sistem panen

Sistem Panen yang berlaku di Divisi 2 GSE adalah sistem hanca giring tetap per mandoran. Setiap pemanen mempunyai hanca yang tetap. Akan tetapi hanca panen dapat berubah sesuai persentase kematangan buah yang disesuaikan dengan kemampuan masing-masing pemanen. Jika persentase kematangan buah tinggi, pemanen diberikan hanca yang lebih kecil dari luas hanca tetap. Sebaliknya, bila persentase kematangan buah rendah, pemanen diberikan hanca yang lebih luas dari hanca tetap. Sistem panen ini berjalan efektif di Divisi 2. Kekurangan dari sistem ini adalah bila pemanen mendapat hanca yang bukan hanca tetapnya, pemanen cenderung tidak menjaga kualitas panennya seperti adanya ditemukan pelepah sengkleh dan susunan pelepah tidak $U$ shape front stacking. Pembagian hanca ini sepenuhnya adalah wewenang mandor panen. Oleh karena itu diharapkan proses supervisi oleh mandor panen tetap dilaksanakan dengan baik untuk menjaga kualitas panen tetap baik.

\section{Kebutuhan tenaga kerja}

Komponen kebutuhan tenaga kerja dihitung dari luasan areal panen dalam satu afdeling, kemampuan rata-rata pemanen per hari, dan pusingan atau rotasi panen yang digunakan. Kemampuan rata-rata pemanen mengacu pada kegiatan panen selama satu hari kerja atau setara dengan 7 jam. Berikut ini adalah contoh perhitungan tenaga kerja panen yang ada di Divisi 2 :

$$
\begin{aligned}
& \text { Luas areal panen : : } 990 \text { ha } \\
& \text { Kemampuan pemanen : } 3.8 \text { ha } \\
& \text { Seksi panen } \quad: 6 / 7 \\
& \text { Kebutuhan tenaga panen } \\
& \begin{array}{l}
=\frac{\text { Luas areal panen }}{\text { seksi panen } \times \text { kemampuan panen }} \\
=\frac{990 \text { ha }}{6 \text { seksi } \times 3.8 \text { ha per hari }}=44
\end{array}
\end{aligned}
$$

Berdasarkan perhitungan di atas, tenaga kerja pemanen yang dibutuhkan adalah 44 orang. Akan tetapi jumlah tenaga pemanen yang ada di Divisi 2 saat bulan Mei adalah 41 orang. Hal ini 
menunjukkan tenaga panen efektif untuk setiap harinya belum terpenuhi. Kurangnya tenaga kerja pemanen akan mengakibatkan panen tidak tuntas karena luas areal panen melebihi kemampuan rata-rata pemanen. Pusingan panen juga menjadi tinggi akibat pengulangan panen pada hanca yang belum tuntas akibatnya jumlah buah lewat matang bertambah dan berpotensi menjadi kehilangan produksi. Untuk mengatasi hal tersebut, mandor mengambil kebijakan dengan memerintahkan pemanen yang belum tuntas hancanya agar membantu pemanen lain yang belum tuntas. Keputusan ini berjalan efektif karena pemanen termotivasi dengan adanya premi lebih basis borong.

\section{Tenaga kerja pemanen}

Tenaga kerja pemanen yang terdaftar di Divisi 2 Gunung Sari Estate pada Bulan Mei tahun 2011 adalah 83 orang (41 cutter dan 42 picker). Pengontrolan tenaga kerja pemanen perlu dilakukan untuk mengetahui kualitas kerja pemanen apakah sudah sesuai dengan Standar Operasional Procedure (SOP) panen yang ditetapkan oleh perusahaan dan agar produksi yang terealisasi dapat sesuai dengan rencana tahunan kebun. Pengontrolan tenaga kerja panen dilakukan dengan mengamati kualitas dan kuantitas kerja pemanen. Pengamatan kualitas kerja pemanen yang dilakukan penulis yaitu pengamatan persentase buah matang tidak dipanen. Pengamatan dilakukan dengan mengambil dua kelompok kecil pemanen (KKP) dari setiap mandoran. Hasil pengamatan disajikan pada Tabel 6 .

Pada Tabel 6, dapat dilihat bahwa persentase buah matang tidak dipanen masih di atas standar yang ditetapkan oleh Gunung Sari Estate yaitu $2.46 \%$ per KKP. Standar buah matang tidak dipanen di Gunung Sari Estate adalah $0 \%$. Tingginya persentase buah matang tidak dipanen disebabkan oleh kelalaian pemanen, pemanen kadang kurang teliti dalam melihat buah matang di pokok. Faktor lain yang mempengaruhi adalah keadaan pokok dan keadaan areal. Pada pokok yang tunasannya tidak baik, brondolan buah biasanya tersangkut di pelepah sehingga pemanen akan kesulitan dalam menentukan kematangan buah tersebut. Keadaan areal yang berpalung akan menyulitkan pemanen dalam memanen buah.

Tabel 6. Hasil pengamatan TBS tidak terpanen di Divisi 2 Gunung Sari Estate

\begin{tabular}{lccc}
\hline KKP & Total TBS dipanen & Buah matang tidak dipanen & \% Buah matang tidak dipanen \\
\hline KKP 1 & 60 & 1 & 1.67 \\
KKP 2 & 81 & 0 & 0 \\
KKP 3 & 73 & 1 & 1.37 \\
KKP 4 & 80 & 1 & 1.25 \\
KKP 5 & 62 & 4 & 6.45 \\
KKP 6 & 50 & 2 & 4 \\
\hline Total & 406 & 9 & 14.74 \\
\hline & & 1,5 & 2.46 \\
\hline
\end{tabular}

TBS yang mempunyai gagang panjang dipotong serapat mungkin dengan buah, tetapi tidak sampai melukai atau menyebabkan terpotongnya brondolan atau terikut ke gagang panjang. Selama menjadi pendamping mandor penulis mengamati hasil losses brondolan akibat pemotongan gagang panjang. Hasil pengamatan disajikan pada tabel 7.

Tabel 7. Hasil pengamatan losses brondolan akibat pemotongan gagang panjang

\begin{tabular}{lcccc}
\hline Mandoran & Jumlah TPH & Losses Brondolan (buah) & Jumlah TBS (tandan) & Brondolan/TBS \\
\hline A & 19 & 114 & 220 & 0.52 \\
B & 19 & 64 & 250 & 0.26 \\
C & 19 & 230 & 410 & 0.56 \\
\hline Total & 57 & 408 & 880 & 0.45 \\
\hline
\end{tabular}

Hasil pengamatan dapat dilihat bahwa jumlah brondolan yang terbuang akibat pemotongan gagang panjang adalah 0.45 brondolan per TBS. Persentasenya memang tidak terlalu besar tapi ini merupakan sumber losses dan perlu diwaspadai. Menurut Pahan (2008) produksi yang maksimal hanya dapat dicapai jika losses produksi minimal. Oleh karena itu perlu ditingkatkan keterampilan pemanen dan pengontrolan oleh mandor panen dalam memotong gangang panjang. 
Tabel 8. Rekapitulasi hasil pengamatan kualitas kutip brondolan

\begin{tabular}{|c|c|c|c|c|c|c|c|}
\hline \multirow{2}{*}{ KKP } & \multicolumn{3}{|c|}{ Brondolan tinggal } & \multirow{2}{*}{ Total } & \multicolumn{3}{|c|}{ Persentase brondolan tinggal } \\
\hline & Piringan & Pokok & Pasar rintis & & Piringan & Pokok & Pasar rintis \\
\hline KKP 1 & 129 & 53 & 29 & 211 & 61.14 & 25.12 & 13.74 \\
\hline KKP 2 & 79 & 28 & 0 & 107 & 73.83 & 26.17 & 0 \\
\hline KKP 3 & 195 & 56 & 23 & 274 & 71.17 & 20.44 & 8.39 \\
\hline KKР 4 & 59 & 80 & 2 & 141 & 41.84 & 56.74 & 1.42 \\
\hline KKP 5 & 39 & 116 & 1 & 156 & 25 & 74.36 & 0.64 \\
\hline KKP 6 & 55 & 61 & 7 & 123 & 44.72 & 49.59 & 5.69 \\
\hline Rata-rata & 92.67 & 65.67 & 10.33 & 168.67 & 52.95 & 42.07 & 4.98 \\
\hline
\end{tabular}

Hasil pengamatan mengenai kualitas kutip brondolan, yaitu meliputi brondolan tinggal, baik tertinggal di piringan, pokok sawit dan pasar rintis. Pengamatan dilakukan dengan melihat kinerja picker (pembrondol) dalam kelompok kecil pemanen (KKP). Dalam satu KKP jumlah pembrondol mengikuti jumlah pemanen yaitu 3 orang pembrondol. Hasil pengamatan dapat dilihat pada Tabel 8 . Tabel 8 di bawah terlihat bahwa persentase brondolan tinggal di piringan paling tinggi yaitu $52.95 \%$. Tingginya persentase brondolan tinggal di piringan disebabkan oleh kelalaian pembrondol dan kondisi piringan kurang baik yaitu banyak ditumbuhi gulma sehingga menyulitkan pembrondol dalam mengutip brondolan. Persentase buah tinggal di pokok juga tinggi yaitu $42.67 \%$. Brondolan tinggal di pokok disebabkan oleh kelalaian pemanen (cutter). Pemanen tidak mengutip brondolan yang tertinggal di bawah janjang panen dan brondolan yang tercecer akibat penggancuan dan pengangkutan mamakai angkong.

Gunung Sari Estate menetapkan standar brondolan tinggal 2 buah brondolan per TBS. Penulis juga melakukan pengamatan brondolan tinggal per pokok berdasarkan jumlah picker dalam KKP. Hasil pengamatan dapat dilihat pada Tabel 9. Hasil pengamatan pada Tabel 9 brondolan yangtertinggal per TBS masih di atas standar yang ditetapkan di Gunung Sari Estate yaitu $2.55 \%$ artinya terdapat 2.55 brondolan per TBS. Oleh karena itu perlu dilakukan peningkatan pengawasan panen untuk meminimalkan kehilangan panen.

Tabel 9. Pengamatan brondolan tinggal per TBS dan per pokok panen

\begin{tabular}{|c|c|c|c|c|c|c|c|c|}
\hline \multirow{2}{*}{$\begin{array}{l}\text { Picker } \\
\text { dalam } \\
\text { KKP }\end{array}$} & \multicolumn{3}{|c|}{ Brondolan tinggal } & \multirow[b]{2}{*}{ Total } & \multirow{2}{*}{$\begin{array}{c}\text { Jumlah } \\
\text { TBS }\end{array}$} & \multirow{2}{*}{$\begin{array}{c}\text { Jumlah } \\
\text { pokok } \\
\text { panen }\end{array}$} & \multicolumn{2}{|c|}{ Brondolan Tinggal \% } \\
\hline & Piringan & Pokok & $\begin{array}{l}\text { Pasar } \\
\text { rintis }\end{array}$ & & & & Per TBS & Per Pokok \\
\hline KKP 1 & 129 & 53 & 29 & 211 & 60 & 55 & 3.25 & 3.84 \\
\hline KKP 2 & 79 & 28 & 0 & 107 & 81 & 74 & 1.32 & 1.45 \\
\hline KKP 3 & 195 & 56 & 23 & 274 & 73 & 67 & 3.75 & 4.09 \\
\hline KKP 4 & 59 & 80 & 2 & 141 & 80 & 72 & 1.76 & 1.96 \\
\hline KKP 5 & 39 & 116 & 1 & 156 & 62 & 55 & 2.52 & 2.84 \\
\hline \multirow[t]{3}{*}{ KKP 6} & 55 & 61 & 7 & 123 & 50 & 46 & 2.46 & 2.67 \\
\hline & & Total & & & 406 & 369 & & \\
\hline & & & Rata-r & & & & 2.55 & 2.81 \\
\hline
\end{tabular}

\section{Buah restan}

Pengelolaan hasil panen secepat mungkin bertujuan agar diperoleh minyak dengan kualitas dan kuantitas yang tinggi. Buah restan adalah buah yang tidak sempat dibawa ke pabrik pada hari itu juga yang disebabkan oleh jumlah kendaraan kurang atau karena jalan rusak sehingga tidak bisa dilalui. Secara umum, pada musim penghujan, produksi meningkat, tetapi jalan mengalami banyak kerusakan sehingga menyebabkan tingginya jumlah buah restan. Buah yang telah selesai dipanen harus diangkut segera ke pabrik. Kejadian buah restan di Divisi 2 GSE selama bulan Januari-April 2011 dapat dilihat pada Tabel 10. 
Tabel 10. Kejadian buah restan di Divisi 2 GSE bulan Januari - Mei 2011

\begin{tabular}{lccc}
\hline \multirow{2}{*}{ Bulan } & \multicolumn{3}{c}{ Restan } \\
\cline { 2 - 3 } & Tonase buah restan & Jumlah hari restan & (ton/hari) \\
\hline Januari & 101920 & 9 & 4.08 \\
Februari & 20780 & 2 & 0.83 \\
Maret & 73400 & 6 & 2.94 \\
April & 76030 & 2 & 3.04 \\
Mei & 44760 & 6 & 1.79 \\
\hline
\end{tabular}

Sumber : kantor Divisi 2 GSE (Mei, 2011)

Buah yang telah dikeluarkan di TPH oleh pemanen banyak yang ditinggal, dan tidak sempat diperiksa oleh mandor panen, krani panen maupun mandor transpor. Kejadian buah restan terbanyak terjadi pada bulan Januari yaitu sebanyak 9 kali dengan rata-rata 4,08 ton/ hari. Faktor utama penyebab terjadinya buah restan pada bulan januari adalah tingginya curah hujan pada bulan Januari yang menyebabkan jalan rusak sehingga tidak bisa dilalui oleh truk pengangkut buah.

Kegiatan panen dimulai sejak pagi hari hingga ancak panen tuntas. Untuk menuntaskan panen satu hari, pemanen membutuhkan waktu yang lebih lama, biasanya pemanen harus bekerja hingga sore hari sehingga pengangkutan harus dilaksanakan hingga malam. Proses pengangkutan buah pada malam hari tidak dapat berjalan efektif karena kendala waktu dan tenaga tukang muat. Hal ini menyebabkan buah tidak habis pada hari tersebut. Untuk mengatasi hal ini maka mandor panen harus memastikan bahwa pemanen yang telah selesai panen tidak langsung pulang namun terlebih dahulu membantu pemanen lain yang belum menuntaskan ancak panennya.

\section{KESIMPULAN}

Mutu buah hasil panen di Divisi 2 masih kurang baik. Berdasarkan hasil pengamatan mutu buah panen di Divisi 2 terdapat buah mentah sebanyak $0.7 \%$ (standar $0 \%$ ), buah ripe $88.11 \%$ (standar >95\%), dan buah empty bunch $8.9 \%$ (standar 0\%). Losses TBS dan brondolan kelapa sawit di Divisi 2 masih tergolong di atas standar yang ditetapkan perusahaan. Pengamatan TBS tinggal didapatkan hasil $2.46 \%$ per KKP dan brondolan tinggal $2.55 \%$ per TBS. Hasil pengamatan kualitas kutip brondolan didapatkan hasil persentase brondolan tinggal di piringan paling tinggi $52.95 \%$ dan di pokok $42.67 \%$.

\section{DAFTAR PUSTAKA}

Lubis, A. U. 2008. Kelapa Sawit (Elaeis guineensis Jacq) di Indonesia Edisi 2. Pusat Penelitian Kelapa Sawit Marihat. Medan.

Mangoensoekarjo, S. dan H. Semangun. 2005. Manajemen Agrobisnis Kelapa Sawit. Yogyakarta (ID) : Gajah Mada University Press.

Manual Referensi Agronomi. 2008. Buku Pedoman Teknis Kelapa Sawit (Standar Operating Procedure Manual Agronomic Practice). Jakarta (ID): Minamas Plantation.

Pahan, I. 2008. Panduan Lengkap Kelapa Sawit Manajemen Agribisnis dari Hulu hingga Hilir.. Jakarta (ID): Penebar Swadaya.

Pardamean, M. 2008. Panduan Lengkap Pengelolaan Kebun dan Pabrik Kelapa Sawit. Jakarta (ID): PT Agromedia Pustaka.

Setyamidjaja, D. 2006. Kelapa Sawit.. Yogyakarta (ID): Kanisius. 